\title{
Research on the Inheritance of Beijing's Ancient Capital Cultural from the Perspective of Nighttime Economy: A Case Study of Qianmen and Dashilan
}

\author{
Wenjing Fan*, Xueqing Dai \\ School of Economics and Management, Beijing Institute of Graphic Communication, Beijing, China \\ *Corresponding author
}

\begin{abstract}
Qianmen and Dashilan was the most important business center in Beijing during the Ming and Qing Dynasties, and it embodies the essence of Beijing's ancient capital culture. With the development of nighttime economy, Qianmen and Dashilan will become the only nighttime economic landmark in the Old City of Beijing. In order to inherit Beijing's ancient capital culture more effectively in the development of nighttime economy, this paper used field visit, consumer interview, questionnaire survey, and expert interview in the study. It focused on the nighttime cultural consumption wishes and demands of young consumers aged 18-45, and summarized the problems in the inheritance of ancient capital culture. Based on the problems, the paper put forward suggestions on how to develop nighttime consumption and inherit Beijing's ancient capital culture from five aspects: enriching nighttime economic formats, building cultural IP, strengthening publicity, improving public service and strengthening government supervision.
\end{abstract}

Keywords: Ancient capital cultural, Inheritance, Nighttime economy, Qianmen and Dashilan

\section{夜经济视角下北京古都文化传承研究一以前门大栅栏为 例}

范文静”, 戴雪晴

北京印刷学院 经济管理学院, 北京, 中国

“通讯作者

中文摘要

前门大栅栏是明清时期北京最重要的商贸中心, 凝聚了北京古都文化的精髓。随着夜经济的发展, 前 门大栅栏将打造成北京老城唯一的夜经济地标。为了在发展夜经济时更有效传承北京古都文化, 文章 采用实地考察、消费者采访、问卷调研、专家访谈的方法, 重点参考 18-45岁年轻消费者的夜间文化消 费意愿和诉求，对前门大栅栏在古都文化传承中存在的问题进行总结梳理。基于现存问题，文章从丰 富夜间经济业态、打造文化IP、强化宣传力度、完善公共服务、加强政府监管五个方面就如何发展夜 间消费，传承古都文化提出对策建议。

关键词: 古都文化; 传承; 夜经济; 前门大栅栏

\section{1. 引言}

夜间经济是城市经济发展的产物，夜间文化消费是 人民群众精神文化需求日益增长的表现。夜间经济活跃
度高低体现了一个城市的开放程度和发展水平, 更体现 了一个城市的文化氛围和生活习惯, 发展夜间经济看似 为了拉动消费, 实则展现的是一个城市的文化元素[1]。 2019年北京实现市场总消费额 27318.9 亿元, 比上年增长 $7.5 \%$ ，其中服务性消费额 15048.8 亿元，比上年增长 
$10.2 \%$ ，占市场总消费的 $55 \%$ 左右，对总消费增长的贡 献率达到 $72.7 \%$ [2], 继续成为拉动总消费增长的主引擎。 北京消费升级特征明显, 尤其焕发活力的夜经济成为 2019年消费市场最大亮点。2019年底腾讯联合瞭望智库 共同发布的《中国城市夜经济影响力报告（2019）》显 示, 北京夜经济影响力位于全国第二。2019年7月发布 的《北京市关于进一步繁荣夜间经济促进消费增长的措 施》中提到: 将前门大栅栏打造为京城夜经济地标, 围 绕古都风貌, 大力发展具有创新引领和品牌吸引力的夜 经济消费业态。前门大栅栏地区珍贵的胡同街巷、丰富 的遗址建筑、浓郁的京味文化、悠久的商业老字号等都 是北京古都风貌的展现。2020年4月《中共北京市委关 于新时代繁荣兴盛首都文化的意见》中将“传承源远流 长的古都文化”放在重要地位, 前门大栅栏作为北京中 轴线上的黄金地段，承担着传承首都文化的重要使命。 夜间文化消费需求的增长为传承古都文化提供了良好 的契机也带来巨大的挑战。丰富夜间文化消费业态，提 升消费品质, 既是促进经济发展的需要, 也是传承古都 文化的途径。

\section{2. 研究区}

北京人的话语中, “前门”常有三个含义: 一是国都 正门正阳门的俗称。二是指正阳门城楼、㸗城、箭楼, 再早还包括正阳桥、五牌楼等构成的城门建筑组合的简 称。三是指前门大街及两侧街巷所组成的明清老商业街 区, 前门大街为街区中心, 大栅栏则是这一片商业街区 最繁华之处。口语中，常以“前门大栅栏”指称这一商业 区[3]。据2001年北京市公布的《北京旧城25片历史文化 保护区保护规划》中所定义的，“前门大栅栏”泛指前门 与大栅栏大街所在的历史街区, 包含前门大街、大栅栏 街、大栅栏西街、杨梅竹斜街、煤市街以及廊坊头条、 二条、三条等在内的众多传统街巷[4]。本文题中所指“前 门大栅栏” 是指北起前门西大街, 南至珠市口大街, 西 起南新华街, 东至前门东路的区域。重点研究前门大街、 大栅栏街、大栅栏西街、杨梅竹斜街、煤市街、鲜鱼口 街游客密集路段。

\section{3. 前门大栅栏再生与古都文化传承}

公元938年契丹辽国升幽州为陪都，称“辽南京”, 拉开了北京作为国都的序幕。1153年金完颜亮从黑龙江 阿城迁都燕京, 在辽南京城的基础上扩建金中都, 北京 正式成为国都。北京古都文化是指围绕北京建都以及北 京成为都城后形成的与都城性质关系密切的物质文化、 制度文化和精神文化的总和[5], 是北京地域性文化与都 城功能性文化的相互交融, 是首都文化的根脉[6]。北京 古都文化表现形式丰富, 前门大栅栏作为明清时期最繁
华的商贸中心，绵亘500多年的文化是古都文化的典范。 新中国成立后, 前门大栅栏的再生是对古都文化的传承 和创新。

前门大栅栏兴起于明代, 明定都后为了发展京城内 外的商业, 由朝廷出钱, 在钟楼、鼓楼以及各处城门周 边修建铺房。铺房多用于堆放货物, 又被称为“廊房”。 廊房头条、廊房二条等胡同名字皆源自此意。大栅栏最 初的名字即为廊房四条。清代时, 前门大栅栏地区已经 成为百业俱全、商贾云集的地方，曾有“京师之精华尽 在于此，热闹繁华莫过于此”的美誉。全聚德的烤鸭、 都一处的烧卖、功德林的素菜、月盛斋的酱肉、聚庆斋 的糕点、长盛魁的干果、六必居的酱菜、张一元的茶叶、 同仁堂的中药等琳琅满目, 五味俱全。还有众多娱乐场 所, 广德楼、庆乐园、三庆园、广和园、同乐园等, 红 飞翠舞, 热闹非凡。1900年义和团运动一把大火将大栅 栏付之一炬, 前门大栅栏的繁华落下帷幕。

20世纪60年代, 前门大栅栏迎来第一次整修, 修筑 了北京第一条柏油路, 再次成为当时的北京商业中心。 此后, 随着北京营商环境改善, 前门大栅栏因消费档次 不高、购物环境差等原因逐渐萧条。20世纪90年代末， 前门大栅栏进行了第二次路面整修和环境整治。2008年 奥运会前, 前门大栅栏进行了第三次大规模改造。改建 后的商业街店铺、牌匾、街道等都尽力展现北京古城风 貌。2011年北京市启动“大栅栏更新计划”，摒弃之前整 体搬迁的刚性模式，采用居民自愿腾退，微循环有机更 新的模式, 实线城市的软性生长。

如今, 前门大栅栏在建筑艺术、民居饮食、商贸制 度、民风习俗、曲艺娱乐等方面均表现出古都文化特征。 古都文化传承过程可归纳为: 风貌改造整旧如旧, 力求 展现沧桑古城风貌; 恢复和繁荣老字号, 传承商业文化 灵魂; 保护会馆故居, 活化文物利用; 依托非遗资源, 传承京味文化; 商业业态开放包容, 满足现代与传统多 元需求。

\section{4. 夜经济下前门大栅栏古都文化传承现存问 题}

为了更有效地打造夜间经济地标, 传承古都文化, 文章在研究中采用实地考察、消费者采访、问卷调研、 专家访谈的形式，对前门大栅栏夜间文化消费相关问题 展开调研。基于夜间消费人群年轻化的特点[7], 文章重 点参考 18-45岁年轻消费者的认知和消费意愿, 收回有效 问卷264份。264位受访者中有 142 人长期居京，占 $53.9 \%$ 。 在前门大栅栏夜间文化消费需求方面, 美食、相声曲艺、 古城风貌、时尚购物、夜间书店方面均有超过半数的需 求度。此外, 创意游乐、文化展览需求度亦较高（详见 表1）。 


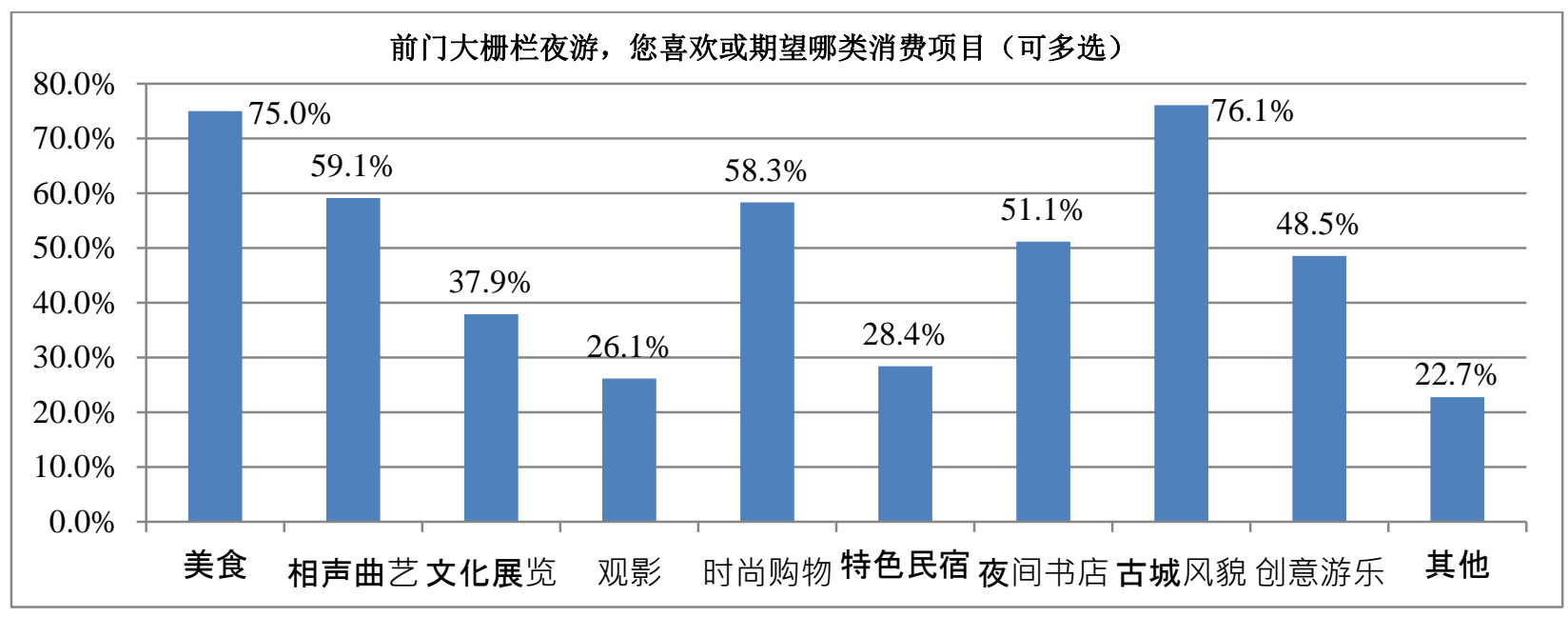

图1 前门大栅栏夜游消费倾向

表1 夜游前门大栅栏旅游满意度评价

\begin{tabular}{|c|c|c|c|c|c|}
\hline & $\begin{array}{c}\text { 非常满意 } \\
\text { 人数 (百分 } \\
\text { 比) }\end{array}$ & $\begin{array}{c}\text { 比较满意 } \\
\text { 人数 (百分比) }\end{array}$ & $\begin{array}{c}\text { 一般 } \\
\text { 人数（百分比 } \\
\text { ) }\end{array}$ & $\begin{array}{c}\text { 不满意 } \\
\text { 人数 (百分比) }\end{array}$ & $\begin{array}{c}\text { 非常不满意 } \\
\text { 人数(百分比) }\end{array}$ \\
\hline 传统文化氛围 & $39(26.4 \%)$ & $43(29.1 \%)$ & $48(32.4 \%)$ & $12(8.1 \%)$ & $6(4.1 \%)$ \\
\hline 文化消费多样性 & $20(13.5 \%)$ & $24(16.2 \%)$ & $57(38.5 \%)$ & $30(20.3 \%)$ & $17(11.5 \%)$ \\
\hline 景区拥挤程度 & $18(12.2 \%)$ & $30(20.3 \%)$ & $82(55.4 \%)$ & $12(8.1 \%)$ & $6(4.1 \%)$ \\
\hline 交通状况 & $22(14.9 \%)$ & $29(19.6 \%)$ & $28(18.9 \%)$ & $38(25.7 \%)$ & $31(20.9 \%)$ \\
\hline 物价水平 & $18(12.2 \%)$ & $16(10.8 \%)$ & $64(43.2 \%)$ & $36(24.3 \%)$ & $14(9.5 \%)$ \\
\hline 治安状况 & $65(43.9 \%)$ & $52(35.1 \%)$ & $18(12.1 \%)$ & $13(8.9 \%)$ & $0(0.0 \%)$ \\
\hline 服务水平 & $27(18.2 \%)$ & $40(27.0 \%)$ & $66(44.6 \%)$ & $9(6.1 \%)$ & $6(4.1 \%)$ \\
\hline
\end{tabular}

264 位受访者中 $\geq 2$ 次前门夜游经验的受访者共 148 位，通过进一步追踪这148受访者对前门大栅栏夜游的 满意度, 得到表1数据。

从表1可知, 受访者对夜间文化消费多样性的评价, 不满意度超过满意度, 另有 $38.5 \%$ 的受访者认为一般。 事实上前门大栅栏区域艺术展览、书店、影城、杜莎夫 人蜡像馆、茶馆、戏楼等文化消费业态均存在，这与图 1 所示文化消费需求的多样性一致, 却与文化消费多样 性满意度相悖。通过进一步的消费者行为分析和专家访 谈, 文章认为这一现象的主要原因一是传统印象误区; 二是文化消费创新不足, 三是宣传途径不够与时俱进。 另外，通过对夜间消费交通状况满意度的调研， $46.6 \%$ 的受访者认为不满或非常不满, 体现了夜间经济对公共 服务的刚性需求。梳理调研结果, 夜经济下前门大柾栏 古都文化传承主要问题如下:

\section{1. 传统印象误区}

传统印象误区, 是指前门大栅栏虽是外地游客来京 首选, 但在北京本地居民印象中却是旅游购物之地。大
多数北京本地居民夜间消费不会选择前门大栅栏, 一是 由于距离带来的交通和时间限制，二是对夜间文化消费 项目不够了解, 根本不知北京坊、戏楼等的晚间展览和 演出。而对于外地游客而言, 美食、购物、古城风貌是 常规选择，其他文化消费需求则是时间充裕时的锦上添 花之选。

\section{2. 商品文化内涵不足}

研究区内前门大街、大栅栏大街、鲜鱼口街等知名 街巷注重知名商业老字号的引入, 但是老字号内所售商 品的创新性与实用性仍显欠缺, 如今人们越来越喜欢文 化的创意表达, 商业老字号亦应注重传统商品与现代社 会的密切联系, 赋予传统商品更多的现代社会功能。另 外, 虽然主要街巷商铺以老字号居多, 但人流较少的街 巷小店, 出售的多是各地景区常见的丝巾、旗袍、手链、 小玩具等, 商品重复率高, 缺乏特色。饮食方面, 老北 京炸酱面、老北京涮肉、老北京爆肚、老北京卤煮等都 持有 “正宗老北京” 名号, 但过多的 “正宗” 反而让人 觉得流失了 “正宗” 二字的文化价值。 


\section{3. 宣传力度不够}

前门大栅栏虽然盛名在外，但上文图1和表1的相关 数据可见前门大栅栏在宣传上力度不足。通过微博、微 信端检索发现, 前门大栅栏并没有形成一个以自己为主 导的、集中的、面向多元群体的官方宣传渠道。现有官 方账号大多是街道工会、老字号商铺、商会自发建立的 公众平台, 且内容更新频率较低, 宣传力度分散, 不利 于游客及时了解该地区的夜间活动文化活动。反观其他 “夜京城”地标如五棵松华熙LIVE、三里屯太古里均开设 有官网、微信公众号、微博账号、抖音账号等官方宣传 渠道, 不定期更新活动推荐、游玩攻略、人气美食、活 动短视频等。早前, 前门大栅栏地区曾举办: 北京国际 设计周、前门历史文化节、大栅栏旅游购物节、前门大 街上元灯会、天街年市、台湾庙会等节事活动, 其中上 元灯会和天街年市分别举办了三次和两次便终止了 [8]。 2018年北京坊的灯光秀也并未引起较大关注, 之后类似 的大型活动更是鲜少举办。研究表明, 节事活动与本区 域的历史植根联系起来，能赋予实体空间恒久且独特的 文化软资产 [8]。前门大栅栏需要高质量的文化品牌活动, 提高文化消费知名度和美誉度, 改变人们对前门大栅栏 的固有印象。

\section{4. 配套设施仍需改进}

市政交通方面: 地铁交通，2号线前门站末班车时 间为22:14。公交汽车交通, 夜2路贯穿南北四环、夜 18 路贯穿南北三环, 站点主要分布在中轴线东西两侧, 夜 17路是前门至北京站东, 而其他方向并没有公共汽车交 通。由于前门大栅栏停车难, 绝多数人出行选择公共交 通, 而以上夜间交通服务, 运营时间和涵盖范围均不够, 不利于市内远程游客往返。

景区方面: 前门夜景观光线18:20末班车, 此时夜经 济才刚刚开始。前门有轨电车末班车21:00, 停运较早。 此外, 前门大栅栏公共卫生间数量也较少, 人流量较多 的时段, 现有卫生间数量难以满足游客需求, 调研发现 前门大街人流密集时游客在卫生间外排的长队可以完 全挡住街道, 影响游客正常通行。

\section{5. 政府管理有待完善}

2019年7月北京推出“夜经济13条”，从交通、安全、 餐饮、资金等方面指导夜经济发展。虽然有了指导性文 件, 但在精细化管理上仍然不足 [7], 截至完稿（2020 年4月）北京还没有对夜间经济运营拟定标准, 尤其在 夜间安全管理、业态范围、公共服务、夜间从业人员保 障等方面需要完善管理制度与规范。另外, 前门大栅栏 既是著名的商业区、旅游区又是居民生活区，区域内住 有大量居民, 作为以古都风貌为主的夜经济地标, 如何 在夜景打造、提升活力与居民日常生活之间平衡尤为重 要。

\section{5. 夜经济下前门大栅栏古都文化传承对策建 议}

\section{1. 跨领域融合创新，丰富夜间经济业态}

科技对于文化产业发展而言既是内容也是形式，甚 至在某种程度上而言可以称之为新时期文化产业发展 的生产力[9]。前门大栅栏应充分重视跨领域融合创新, 借助时代科技，打造新的文化产品。如利用3D照明、灯 光布景、全息投影、 $\mathrm{VR}$ 等技术打造沉浸式夜间文化体 验空间。文中图1所示 $48.5 \%$ 的受访者希望在前门大栅栏 夜间文化消费中体验创意游乐, 说明创意游乐几乎已成 为消费中不可或缺的内容, 古城风貌亦需要跨界融合, 打造创新的文化氛围。2019年故宫博物院“紫禁城上元 之夜” 持续几日霸占热搜, 故宫大秀将高新科技与文物 保护相融合, 不仅展示了紫禁城夜景的恢宏瑰丽, 灯光 版《清明上河图》、《千里江山图卷》也向世人展示了 文物保护的新成果 [7]。前门大栅栏亦应利用新科技展示 前门大栅栏 500 余年的繁荣盛貌与风雨历程, 让人们回 顾历史、铭记历史。

另外，开发文化互动活动和情景表演。北京有句俗 语“头顶马聚源, 脚踩内联升, 身穿瑞蚗祥, 腰缠四大 恒”, 曾是北京人身份地位的象征。如今四大恒 (钱庄: 恒利、恒和、恒兴、恒源）没有了, 现代穿衣特征极少 数人能“头顶马聚源, 脚踩内联升, 身穿瑞蚗祥”。可以 根据前门商业特色及其他北京民俗，打造故事性情景演 出, 让人们从头到脚装扮起来, 形成文化互动。心理学 研究表明人在夜晚大脑活动“情绪中枢”作用占上风，更 容易受到情绪支配[10], 情绪带动下的夜间文化体验必 然更加深刻。

\section{2. 打造文化IP，扩大优质供给}

传统文化的创新性发展, 只有外部形式的创新是不 够的, 文化的内涵、深度成为愈来愈显性的需求。而随 着现代文化的快速传播, 文化IP的范围已经非常广, 电 影、文学、文物、传统节日，甚至甲骨文“表情包”都可 以成为文化IP[11]。2017 年故宫博物院所有文创产品总 收入达 15 亿元，在故宫文创成功的背后，我们不能忽视 的是故宫博物院在梳理、保护、研究和历史文化挖掘上 所做的工作，以及针对文创产品开发设计所进行的前期 研究[12]。因此, 前门大栅栏应仅仅围绕“前门大栅栏” 这个关键词展开文化资源的梳理、保护、研究与创意设 计, 花大力气打造文化IP, 形成高质量文化产品供给。 这既是传播首都文化的需要, 也是民众文化消费的需要。

\section{3. 强化宣传力度, 占领年轻群体客户端}

90 后、00 后逐渐成为夜间消费主力, 前门大栅栏 宣传上, 一是应建立微信、微博、今日头条、抖音等新 
媒体官方宣传平台，统筹线上、线下宣传。二是通过微 博互动、直播、微信推送等形式, 利用年轻人喜欢的语 言风格和方式，抓住热点，形成多渠道、多形式、年轻 化的宣传模式。如2020年疫情期间两位明星去红螺寺烧 香被拍, 事后女方“在线被分手”。引发网友质疑“男雍和, 女红螺”, 红螺寺求姻缘到底灵不灵? 红螺寺官微出来 表示这个“锅”我们不背。红螺寺的回应让网友心疼红螺 寺的“委屈巴巴”。抓住年轻群体的话题热点与话语习惯 就是抓住了他们的心。三是邀请明星或网络主播作为夜 间经济推荐官、文化消费体验官等，借鉴“明星+主播”、 “二次元偶像+主播”等直播方式，宣传文化活动，促进 夜间文化消费。

\section{4. 完善公共服务, 提升夜游体验}

市政交通方面: 完善公共设施, 延长夜间公共交通 运营时间，在夜间出行较高的住宅区、商业区、文化街 区等沿线增加夜班公交路线和车次，方便市民夜间出行。

景区方面: 延长夜景观光线运营时间; 适当延长文 化体验场馆、店铺商家运营时间; 增设卫生间、垃圾桶 等卫生服务设施, 维护前门大栅栏整洁; 服务方面, 定 期开展教育培训, 注重对工作人员文化素养和职业道德 意识的培养，提高工作人员的服务质量和水平。

\section{5. 设立专门机构, 加强治理监管}

对于政府而言, 几乎不可能既要发展夜间经济, 又 要杜绝夜间经济造成的各种社会成本[13]。因此, 保障 夜间经济运营，政府首先要投入各种资源。管理上，应 成立专门的管理机构, 在安全管理、业态范围、公共服 务、夜间从业人员保障等方面细化完善管理制度与运营 规范。

另外, Eldridge (2019) 的研究中讲到: 夜间经济 的发展让长期居住在此地的居民在夜晚更容易产生一 种被自己的归属地排斥的感受或担忧, 这种担忧来自他 们对新事物的不熟悉, 在夜晚也更容易因为噪音而感到 焦躁和心烦 [14]。前门大栅栏区域有居民5万余人, 政府 应充分考虑居民的安全感, 在业态分布、夜景打造、夜 晚噪音、夜行安全等方面统筹协调, 保障市民正常的生 活秩序。

\section{6. 结束语}

前门大栅栏以较好的古都风貌和丰富的老字号吸 引了众多国内外文化旅游者。位于煤市街廊坊头条的北 京坊又以古典与现代融合的艺术气息, 成为文艺青年的 时尚生活体验区。前门大栅栏及其周边故宫博物院、国 家大剧院、国家博物馆等丰富的文化资源串联, 在夜经 济中不仅仅应打造为 “夜经济地标” , 更应成为首屈一 指的 “夜间文化地标”。因此, 提供丰富多样的夜间消 费形式，打造高质量、多层次的消费供给是发展夜间经
济的必然趋势。依托现有文化资源融合科技创新，让古 都文化成为 “活” 的文化，既是传播首都文化价值的过 程也是文化自觉与文化自信形成的过程。

\section{致谢}

本文为北京市教委科研计划一般项目北京夜间文 化旅游提升路径研究（SM202010015003）的阶段性成 果之一。

\section{REFERENCES}

[1] W. Q. Zhu. "Cultural elements should be infused into night economy", United Daily News, 2019-06-26 (2). (in Chinese)

[2] Information on http://bj.people.com.cn/n2/2020/0302/c82839-33841730 .html

[3] Beijing Tourism Training and Examination Center, Beijing Tourism Guide (I), Tourism Education Press, Beijing, 2013. (in Chinese)

[4] Q. L. Wu, N. Guan. "A comparative study on the vitality of Qianmen and Dashilan historical districts based on network data", in Invigorating Urban and Rural Residents: Proceedings of 2019 China Urban Planning Annual Conference (05 Application of New Urban Planning Technologies), China Construction Industry Press, Beijing, 2019. (in Chinese)

[5] B. Zhang. "The essence of Beijing's ancient capital culture", People's Tribune, No. 18, pp. 136-137, 2018. (in Chinese)

[6] W. Ch. Guo, X. X. Meng. "The orientation, connotation and internal logic of capital culture", Journal of Frontline, No. 2, pp. 77-79, 2018. (in Chinese)

[7] W. J. Fan. "Demands analysis and development suggestions for museum night tour in Beijing", Sustainable Development, Vol. 10, No. 2, pp. 167-174, 2020. (in Chinese)

[8] Sh.Y. Zhou, L. P. Wu, R. H. Zhang. "An analysis of the relation between festivals and production of space", Geographical Research, Vol. 30, No. 10, pp. 1994-2002, 2015. (in Chinese)

[9] Zh. Fan. "Innovation and development of cultural industry in the revolution of digital economy", Journal of Shenzhen University (Humanities \& Social Sciences), Vol. 37, No. 1, pp. 50-56, 2020. (in Chinese) 
[10] X. D. Fu. "Night economy stimulates new momentum of urban governance", People's Tribune, No. 19, pp. 48-51, 2019. (in Chinese)

[11] Y. W. Jia. "Cultural heritage creative survival and traditional cultural innovation development from the perspective of cultural and creative design", Arts Criticism, No. 9, pp. 83-88, 2019. (in Chinese)

[12] N. Hu. "The innovation of traditional culture communication presents the characteristics of the times", China Culture Daily, 2019-07-27(001). (in Chinese)

[13] Zh. G. Mao, Y. N. Long, X. Ye. "Research progress on nighttime economy", Economic Perspectives, No. 2, pp. 103-116, 2020. (in Chinese)

[14] A. Eldridge. "Strangers in the night: Nightlife studies and new urban tourism", Journal of Policy Research in Tourism, Leisure and Events, Vol. 11, No. 3, pp. 1-14, 2019. 